\title{
Síndrome por sobreuso en el codo del paciente laboral
}

\section{Overuse syndrome in the elbow of the occupational patient}

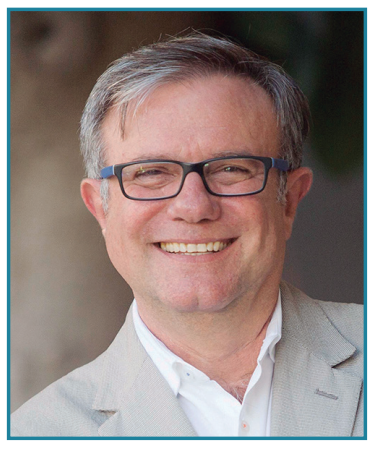

Dr. Eduardo Sánchez Alepuz Hospital IMED Valencia
- l codo es el punto de unión entre el hombro y la mano; con su desarrollo filoZ genético, se llegó a constituir una bisagra perfecta que permitiera la flexoextensión estable (articulación humerocubital) y la pronosupinación (articulación radiocubitohumeral), para darle una funcionalidad completa al miembro superior, permitiendo la longitud y la orientación adecuadas de la mano para poder realizar sus funciones correctamente, garantizando el desarrollo y la evolución del ser humano desde mucho antes del Homo sapiens moderno.

Biomecánicamente, el codo es una articulación compleja, cuyas 3 articulaciones (humerocubital, humerorradial y radiocubital) son muy congruentes y estables. A esta estabilidad contribuyen la morfología ósea de estas articulaciones y los tejidos blandos (ligamentos y cápsula) que las contienen. Esta estructura anatómica del codo permite colocar la mano en posición funcional, actuar como fulcro de palanca y como articulación de soporte de cargas. Estas funciones son imprescindibles para las actividades diarias, recreativas, profesionales y deportivas.

Como dice Bernard F. Morrey: "el diagnóstico de las patologías de codo generalmente no es difícil", la dificultad principal radica en la elección del mejor plan terapéutico en cada uno de los momentos de la evolución de las diferentes patologías. Es fundamental una historia clínica meticulosa con una correcta exploración clínica y, en el entorno laboral, discernir entre lesiones agudas versus crónicas o repetitivas, y su correlación o no con la actividad laboral del paciente. Es clave una anamnesis dirigida al dolor: crónico o agudo, localizado o generalizado, calidad y carácter del dolor, cambios en el tiempo, traumatismos repetidos y problemas legales o búsqueda de compensación económica (frecuente en el entorno laboral).

Dos tipos de patologías analizaremos en este monográfico, las lesiones agudas y las crónicas; estas últimas en muchos casos son secundarias a "síndromes por sobreuso", cuadros de dolor y limitación funcional relacionados con la actividad repetida que ejerce el trabajador en su puesto de trabajo, pudiendo ser

FS https://doi.org/10.24129/j.retla.04208.fs2106017

๑ 2021 Sociedad Española de Traumatología Laboral. Publicado por Imaidea Interactiva en FONDOSCIENCE ${ }^{\circledR}$ (www.fondoscience.com). Este es un artículo Open Access bajo la licencia CC BY-NC-ND (www.creativecommons.org/licenses/by-nc-nd/4.0/). 
transitorios o duraderos. El problema que nos planteamos es dónde está la delimitación entre transitorio y duradero, y cuándo podemos reincorporar al paciente después de un periodo de reposo y tratamiento a sus actividades laborales.

Los sindromes por sobreuso normalmente afectan a los músculos o a los nervios y existen muchas denominaciones diferentes: lesiones por cargas repetidas, sindrome de estrés repetitivo, síndrome doloroso crónico, trastornos ocupacionales (codo del tenista, calambre del escritor...). Cualquiera que sea la nominación que empleemos, estos sindromes pueden afectar a todas las estructuras anatómicas del codo: hueso (hipertrofias, cambios angulares), articulación (artrosis, cuerpos libres, lesiones condrales...), sinovial (sinovitis mecánica o reactiva), ligamentos (calcificaciones, elongaciones...), tendones (epicondilitis, epitrocleítis, tendinopatías del bíceps distal...), músculo (sindromes compartimentales, miofascitis...) y nervios (atrapamiento del túnel cubital, arcada de Frohse...).

Los sindromes por sobreuso se dan fundamentalmente en 2 tipos de pacientes: artistas/deportistas y trabajadores manuales. En todos ellos, si analizamos los factores etiopatogénicos, encontraremos mecanismos de repetición (muchas repeticiones en poco tiempo o repeticiones continuas en todas la jornadas laborales o entrenamientos deportivos o artísticos). Otro factor desencadenante de un síndrome por sobreuso es la adopción de posiciones no fisiológicas o antinaturales para la ejecución de la actividad laboral o la presencia de una patología de base en el codo. Generalmente, los síndromes por sobreuso surgen de la combinación de cargas estáticas y dinámicas sobre las diferentes estructuras anatómicas del codo más allá del nivel de contracción o duración tolerable.

La Asociación Japonesa de la Salud Laboral ha identificado varios factores de riesgo para el desarrollo del sindrome por sobreuso: la contracción dinámica del músculo para tareas repetidas, la contracción estática del músculo para el soporte postural, posturas incómodas, estrés mental y factores ergonómicos no adecuados en el puesto de trabajo.

Es fundamental identificar el síndrome por sobreuso, asi como sus factores etiopatogénicos, cuadro clínico y los factores de riesgo y desencadenantes. No existe un tratamiento único o estándar del síndrome por sobreuso, pero debemos basarlo en el tratamiento agudo del dolor (reposo de la actividad física, medidas antiinflamatorias locales y sistémicas, medidas rehabilitadoras...), el tratamiento específico del cuadro clínico que genera el sindrome por sobreuso, valorar los factores desencadenantes y realizar cambios ergonómicos en el puesto de trabajo para evitar las recaídas, tan frecuentes en este tipo de patología laboral.

En conclusión, el síndrome por sobreuso es un cuadro patológico mal comprendido y analizado al cual, por su frecuencia y repercusión en procesos de larga incapacidad laboral y coste económico, deberíamos prestar más atención para detectarlo dentro del mundo laboral, además de desarrollar claras definiciones del síndrome, clasificaciones, diagnósticos y tratamientos. Son fundamentales los estudios epidemiológicos para establecer medidas preventivas y ergonómicas en los puestos de trabajo y concienciar y educar a empresarios, trabajadores y responsables mutuales, tanto directivos médicos como personal sanitario.

\section{Dr. Eduardo Sánchez Alepuz Hospital IMED Valencia}

